\title{
Mengatasi Imbalanced Class Pada Software Defect Prediction Menggunakan Two-Step Clustering-Based Undersampling dan Bagging Tehcnique
}

\author{
Muhammad Faittullah Akbar ${ }^{1}$, Ilham Kurniawan ${ }^{2}$, Ahmad Fauzi ${ }^{3}$ \\ ${ }^{1}$ Universitas Bina Sarana Informatika \\ e-mail: muhammad.mt|@bsi.ac.id \\ 2 Universitas Bina Sarana Informatika \\ e-mail: ilham.imk@bsi.ac.id \\ ${ }^{3}$ Universitas Bina Sarana Informatika \\ e-mail: ahmad.fzx@bsi.ac.id
}

\begin{abstract}
Abstrak
Ketidakseimbangan kelas seringkali menjadi masalah di berbagai set data dunia nyata, di mana satu kelas (yaitu kelas minoritas) berisi sejumlah kecil titik data dan yang lainnya (yaitu kelas mayoritas) berisi sejumlah besar titik data. Sangat sulit untuk mengembangkan model yang efektif dengan menggunakan data mining dan algoritma machine learning tanpa mempertimbangkan preprocessing data untuk menyeimbangkan set data yang tidak seimbang. Random undersampling dan oversampling telah digunakan dalam banyak penelitian untuk memastikan bahwa kelas yang berbeda mengandung jumlah titik data yang sama. Dalam penelitian ini, kami mengusulkan kombinasi two-step clustering-based random undersampling dan bagging technique untuk meningkatkan nilai akurasi software defect prediction. Metode yang diusulkan dievaluasi menggunakan lima set data dari repositori program data metrik NASA dan area under the curve (AUC) sebagai evaluasi utama. Hasil telah menunjukkan bahwa metode yang diusulkan menghasilkan kinerja yang sangat baik untuk semua dataset $(A \cup C>0,9)$. Dalam hal $S N$, percobaan kedua mengungguli percobaan pertama di hampir semua dataset (3 dari 5 dataset). Sementara itu, dalam hal SP, percobaan pertama tidak mengungguli percobaan kedua di semua dataset. Secara keseluruhan percobaan kedua mengungguli dan lebih baik daripada percobaan pertama karena evaluasi utama dalam klasifikasi kelas yang tidak seimbang seperti SDP adalah AUC Oleh karena itu, dapat disimpulkan bahwa metode yang diusulkan menghasilkan kinerja yang optimal baik untuk set data skala kecil maupun besar.
\end{abstract}

Keywords: Ketidakseimbangan kelas, Machine Learning, Clustering, Ensemble Classifier.

\begin{abstract}
limbalances class are often a problem in a variety of real-world data sets, where one class (i.e. minority class) contains a small number of data points and the other (i.e. majority class) contains a large number of data points. It is very difficult to develop effective models using data mining and machine learning algorithms without considering preprocessing data to balance unbalanced data sets. Random undersampling and oversampling have been used in many studies to ensure that different classes contain the same number of data points. In this study, we propose a combination of two-step clustering-based random undersampling and bagging technique to increase the accuracy of software defect prediction. The proposed method was evaluated using five data sets from the NASA metric data program repository and area under the curve (AUC) as the main evaluation. Results have shown that the proposed method produces very good performance for all datasets (AUC> 0.9). In the case of SN, the second experiment outperformed the first experiment in almost all datasets ( 3 of 5 datasets). Meanwhile, in the case of SP, the first trial did not outperform the second trial in all datasets. Overall the second experiment outperformed and was better than the first experiment because the main evaluation in class classification that was imbalanced class like SDP was AUC. Therefore, it could be concluded that the proposed method produced optimal performance for both small and large scale data sets.
\end{abstract}

Keywords: limbalance Class, Machine Learning, Clustering, Ensemble Classifier. 


\section{Pendahuluan}

Software defect prediction (SDP) adalah proses memprediksi bagian mana dari kode yang rusak dan mana yang tidak (Siers \& Islam, 2015). Prediksi akurat dari modul perangkat lunak rawan cacat dapat membantu upaya pengujian secara langsung, mengurangi biaya dan juga meningkatkan proses pengujian perangkat lunak dengan berfokus pada modul rawan kesalahan (Catal, 2011). Dalam data mining dan machine learning, sulit untuk melatih model pembelajaran yang efektif jika distribusi kelas dalam set data pelatihan yang diberikan tidak seimbang. Ini dikenal sebagai masalah ketidakseimbangan kelas. Satu kelas mungkin diwakili oleh sejumlah besar contoh, sedangkan contoh yang lain mungkin diwakili oleh hanya beberapa. Selain itu, untuk sebagian besar algoritma data mining (Lin, Tsai, Hu, \& Jhang, 2017).

Tanpa mempertimbangkan masalah ketidakseimbangan kelas, algoritma pembelajaran atau model yang dibangun dapat dikuasai oleh kelas mayoritas dan dapat mengabaikan kelas minoritas. Sebagai contoh, pertimbangkan kumpulan data dua kelas dengan rasio ketidakseimbangan 99\%, di mana kelas mayoritas merupakan 99\% dari kumpulan data dan kelas minoritas hanya mengandung $1 \%$. Untuk meminimalkan tingkat kesalahan, algoritma pembelajaran mengklasifikasikan semua contoh ke dalam kelas mayoritas, yang menghasilkan tingkat kesalahan 1\%. Dalam hal ini, semua contoh milik kelas minoritas adalah yang terpenting dan harus diidentifikasi sebagai klasifikasi yang salah (Learning, Liu, Wu, Zhou, \& Member, 2009).

Berbagai metode telah diusulkan untuk menyelesaikan masalah ini. Metode tersebut dapat dibagi menjadi empat jenis: metode tingkat algoritmik, metode tingkat data, metode cost sensitive, dan ensemble clasification (Galar, Fern, Barrenechea, \& Bustince, 2012). Secara khusus, metode tingkat data, yang fokus pada preprocessing set data yang tidak seimbang sebelum membangun pengklasifikasi, secara luas dipertimbangkan dalam literatur. Ini karena tugas-tugas preprocessing data dan pelatihan classifier dapat dilakukan secara independen. Selain itu, menurut Galar et al. (Galar et al., 2012), yang melakukan studi perbandingan berbagai pendekatan terkenal, kombinasi metode preprocessing data dengan ensemble classifier berkinerja lebih baik daripada metode lain.

Metode data preprocessing didasarkan pada resampling set data pelatihan yang tidak seimbang sebelum tahap pelatihan model. Untuk menciptakan keseimbangan, set data ketidakseimbangan yang asli dapat disampel ulang dengan melakukan oversampling kelas minoritas (Hu, 2009) dan / atau undersampling kelas mayoritas (Li, Liu, \& Hu, 2010). Beberapa pendekatan representatif menggabungkan preprocessing data oversampling dan undersampling dengan ensemble classifier melalui teknik boosting (Schapire, 1990) atau bagging (Bbeiman, 1996); misalnya SMOTEBoost (Chawla, Lazarevic, Hall, \& Bowyer, n.d.), RUS Boost (Seiffert, Khoshgoftaar, Hulse, \& Napolitano, 2010), OverBagging (Solis, Avizzano, \& Bergamasco, 2002), dan UnderBagging (Barandela, Sánchez, \& Valdovinos, 2003).

Sebagian besar pendekatan ini melakukan beberapa putaran resampling acak untuk kelas mayoritas (misalkan undersampling) atau minoritas (misalkan oversampling). Dalam kelompok metode berikutnya, set pelatihan seimbang yang berbeda digunakan untuk melatih sejumlah pengklasifikasi spesifik untuk kombinasi selanjutnya sebagai ensemble classifier. Dari dua strategi resampling ini, undersampling telah terbukti menjadi pilihan yang lebih baik daripada oversampling (Galar et al., 2012). Ini karena strategi oversampling dapat meningkatkan kemungkinan overfitting dalam proses konstruksi model. Namun, dengan strategi undersampling, beberapa data berguna yang hadir di kelas mayoritas mungkin dihilangkan (Sun et al., 2015).

Untuk mengatasi keterbatasan undersampling, kami mengusulkan untuk mengganti strategi random undersampling dengan teknik clustering. Tujuan dari analisis clustering adalah untuk mengelompokkan objek yang serupa (yaitu sampel data) ke dalam kelompok yang sama; objek dalam kelompok berbeda, berbeda dalam hal representasi fitur mereka (Jain, A, Murty, M, \& Flynn, P, 1999). Oleh karena itu, menggunakan analisis pengelompokan untuk menggaris bawahi kelas mayoritas menghasilkan sejumlah cluster, dengan masing-masing 
cluster berisi data yang sama. Secara khusus, setiap cluster centroid (atau pusat), yang didasarkan pada rata-rata data yang sama dalam kelompok yang sama yang dihitung oleh algoritma k-means (Hartigan \& Wong, 1979), dapat digunakan untuk mewakili data dalam seluruh kelompok. Dengan kata lain, data asli dalam kelompok yang sama diganti oleh pusat-pusat cluster, sehingga mengurangi ukuran kelas mayoritas.

Dalam penelitian ini, kami menunjukkan bahwa jenis strategi undersampling berbasis clustering, ini dapat mengurangi risiko menghapus data yang berguna dari kelas mayoritas, memungkinkan pengklasifikasi yang dibangun (termasuk kedua pengklasifikasi tunggal dan ensemble classifier) untuk mengungguli pengklasifikasi yang dikembangkan menggunakan strategi random undersampling. Kami mengusulkan kombinasi two-step cluster (TSC) clustering-based undersampling (RUS) dan bagging technique (TSC-RUS + B) untuk meningkatkan akurasi SDP. TSC-RUS diterapkan untuk menangani kelas yang tidak seimbang dan teknik bagging digunakan untuk meningkatkan kinerja classifier di SDP. RUS dipilih karena banyak penelitian sebelumnya menggunakan pendekatan ini ketika berhadapan dengan klasifikasi kelas yang tidak seimbang. Sementara TSC dipilih sebagai algoritma cluster karena TSC dapat menyelesaikan setidaknya beberapa masalah ini, misalnya: kemampuan untuk menangani variabel tipe campuran dan kumpulan data besar, penentuan otomatis jumlah cluster optimal, dan variabel yang mungkin tidak normal (Michailidou, Maheras, Arseni-Papadimititriou, KolyvaMachera, \& Anagnostopoulou, 2009).

\section{Metode Penelitian}

Kami mengusulkan metode yang disebut TSC-RUS + B, two-step clustering based undersampling dan teknik bagging untuk mengatasi masalah kelas yang tidak seimbang dalam prediksi cacat perangkat lunak. TSC adalah salah satu algoritma pengelompokan yang dikembangkan pertama kali oleh (Chiu, Fang, Chen, Wang, \& Jeris, 2001) dan dirancang untuk menangani kumpulan data yang sangat besar. TSC mampu menangani variabel kontinu dan variabel kategorikal (Chiu et al., 2001), (Satish \& Bharadhwaj, 2010). Dalam teknik bagging, Naive Bayes (NB), Logistic Regression (LR), dan k-Nearest Neighbor (kNN), digunakan sebagai pelajar dasar, Support Vector Machine (SVM) digunakan sebagai model testing. Gambar 1 menunjukkan diagram blok dari metode yang diusulkan.

Metode yang diusulkan dievaluasi menggunakan lima dataset program data metrik NASA (NASA MDP), yaitu: CM1, KC1, KC2, MC2, PC1. Seperti yang ditunjukkan pada Gambar 1, lima dataset NASA MDP dikalikan masing-masing dan dimasukkan ke fase pelatihan dan fase pengujian masing-masing; di mana fase pelatihan digunakan untuk membangun model dan fase pengujian digunakan untuk menguji model dan mengevaluasi kinerjanya.

Pada fase pelatihan, dataset kemudian dikelompokkan menggunakan algoritma TSC. Jumlah cluster diatur ke 2, cluster sebagai ide yang sama dengan membuat 2-binning atau 2 kuartil. Kemudian, kami melakukan random undersampling untuk setiap cluster, sehingga kelas mayoritas dan kelas minoritas adalah angka yang sama untuk setiap cluster. Setelah itu, dataset baru dibuat dengan menggabungkan dari semua cluster dengan proporsi yang sama untuk setiap kelas.

Setelah itu, dataset baru adalah teknik bagging dengan pendekatan cross validation 10 kali lipat dimana dataset akan dibagi menjadi 10 bagian dataset, 1 bagian sebagai dataset pengujian dan sisanya sebagai dataset pelatihan dan proses ini diulang 10 kali. Kami menggunakan NB, LR dan kNN sebagai pelajar dasar dan SVM sebagai model testing dalam teknik bagging. Setelah proses pembelajaran selesai, model akan memberi hasil dengan dataset pengujian dalam fase pengujian dan kemudian kami mencatat hasil evaluasi.

Dalam penelitian ini, metode yang diusulkan dievaluasi dengan menggunakan efektivitas classifier berdasarkan confusion matrix dengan evaluasi utama adalah area under the curve (AUC) seperti yang digunakan oleh (Laradji, Alshayeb, \& Ghouti, 2015), (Rana, Mian, \& Shamail, 2015), (Czibula, Marian, \& Czibula, 2014), (Wahono \& Herman, 2014), (Arar \& Ayan, 2015) AUC memiliki potensi untuk secara signifikan meningkatkan konvergensi di seluruh eksperimen empiris dalam prediksi 
cacat perangkat lunak (Laradji et al., 2015) dan penggunaan AUC untuk meningkatkan perbandingan studi silang (Lessmann, Baesens, Mues, \& Pietsch, 2008). Panduan dasar untuk mengklasifikasikan keakuratan tes diagnostik berdasarkan AUC sebagaimana dinyatakan oleh (Gorunescu, 2011) sebagai berikut:

$$
\begin{array}{ll}
\text { - } & 0,90-1,00=\text { klasifikasi sangat } \\
& \text { baik } \\
\text { - } & 0,80-0,90=\text { klasifikasi yang baik } \\
\text { - } & 0,70-0,80=\text { klasifikasi yang adil } \\
\text { - } & 0,60-0,70=\text { klasifikasi buruk } \\
\text { - } & 0,50-0,60=\text { kegagalan. }
\end{array}
$$

Evaluasi lain dari metode yang diusulkan yaitu: recall atau sensitivity (SN) seperti yang digunakan oleh (Laradji et al., 2015), (Czibula et al., 2014), (Wahono \& Herman, 2014); specipies (SP) dan precision (PR) seperti yang digunakan oleh (Czibula et al., 2014), (Wahono \& Herman, 2014).

Evaluasi ini didasarkan pada confusion matrix yang berisi nilai true positive (TP), true negative (TN), false positive (FP) dan false negative (FN) seperti yang ditunjukkan pada Tabel 1. TP berarti ketika label yang diprediksi rusak dan aktual label juga rusak. Ketika label yang diprediksi rusak tetapi label yang sebenarnya tidak rusak, itu disebut FP.

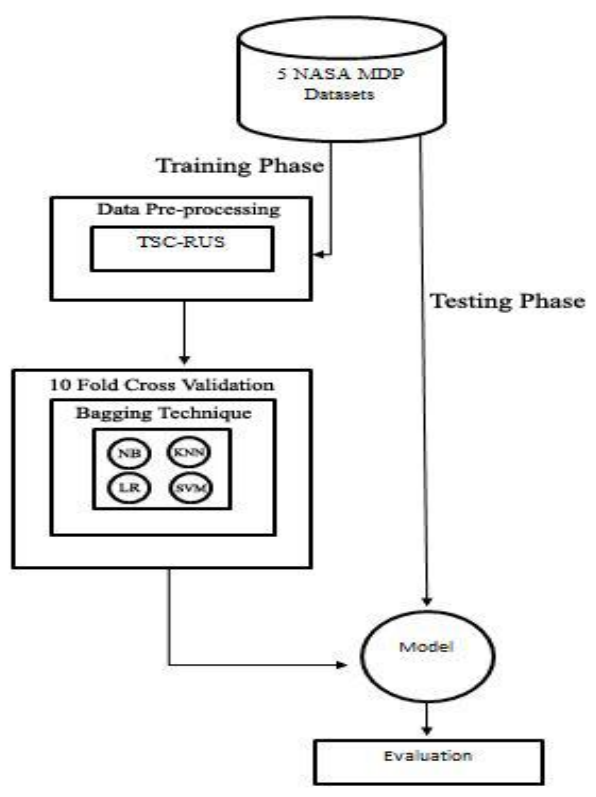

Gambar 1. Block Diagram

TN sama dengan TP tetapi dalam hal label tidak cacat, sedangkan $\mathrm{FN}$ adalah ketika label yang diprediksi tidak rusak tetapi sebenarnya labelnya rusak. Ini dihitung berdasarkan confusion matrix yang dihasilkan dari model. Berdasarkan confusion matrix, perhitungan pengukuran adalah sebagai berikut:

a) $\mathrm{SN}$ : mengukur proporsi instance pola positif yang secara benar diakui sebagai positif

$\mathrm{SN}=\mathrm{TP} /(\mathrm{TP}+\mathrm{FN})$

b) SP: mengukur proporsi instance pola negatif yang dikenali dengan benar sebagai negatif.

$\mathrm{SP}=\mathrm{TN} /(\mathrm{TN}+\mathrm{FP})$

C) PR: mengukur probabilitas bahwa instance pola prediksi positif dilabeli sebagai positif

$\mathrm{PR}=\mathrm{TP} /(\mathrm{TP}+\mathrm{FP})$

Tabel 1. Confusion Matrix

\begin{tabular}{|l|c|c|}
\hline \multirow{2}{*}{ Predicted } & \multicolumn{2}{|c|}{ Actual } \\
\cline { 2 - 3 } & Defective & Non-Defective \\
\hline Defective & TP & FP \\
\hline Non-Defective & FN & TN \\
\hline
\end{tabular}

\section{Hasil dan Pembahasan}

Eksperimen dilakukan dengan menggunakan platform komputasi berbasis AMD Core 2 Duo $1.9 \mathrm{GHz}$ CPU, 2 GB RAM dan sistem operasi Microsoft Windows 10 64-bit, Weka versi 3.9 sebagai alat analisis data. Weka akan menghasilkan AUC dan confusion matrix sebagai hasil perhitungan.

\section{Teknik Bagging}

Pertama-tama, kami melakukan percobaan pada lima dataset MDP NASA dengan teknik bagging saja. Confusion matrix seperti yang ditunjukkan pada Tabel 2 dihasilkan untuk setiap dataset dari Weka dan kemudian kami mengevaluasi metode dengan menghitung SN, SP dan PR, sementara AUC langsung dihitung oleh Weka. Tabel 3 menunjukkan evaluasi metode lengkap.

Tabel 2. Confusion Matrix Tehnik Bagging

\begin{tabular}{|c|c|c|c|c|}
\hline Dataset & TP & TN & FP & FN \\
\hline CM1 & 0 & 42 & 0 & 285 \\
\hline KC1 & 1777 & 6 & 314 & 12 \\
\hline KC2 & 410 & 5 & 81 & 26 \\
\hline PC1 & 2 & 59 & 1 & 643 \\
\hline MC2 & 18 & 26 & 13 & 68 \\
\hline
\end{tabular}


Tabel 3. Metode Evaluasi Untuk Tehnik Bagging

\begin{tabular}{|c|c|c|c|c|}
\hline Dataset & AUC & SN & SP & PR \\
\hline CM1 & $0,778^{\mathrm{c}}$ & 0 & 0,812 & 0,872 \\
\hline KC1 & $0,762^{\mathrm{c}}$ & 0,993 & 0,848 & 0,822 \\
\hline KC2 & $0,768^{\mathrm{c}}$ & 0,940 & 0,797 & 0,835 \\
\hline PC1 & $0,847^{\mathrm{b}}$ & 0,003 & 0,878 & 0,915 \\
\hline MC2 & $0,662^{\mathrm{d}}$ & 0,209 & 0,673 & 0,688 \\
\hline
\end{tabular}

a Sangat baik, ${ }^{\mathrm{b}}$ Baik, ${ }^{\mathrm{c}}$ Biasa, ${ }^{\mathrm{d}}$ Buruk, ${ }^{\mathrm{e}}$ Gagal.

Seperti yang ditunjukkan pada Tabel 3, metode ini menghasilkan 1 AUC dengan klasifikasi baik, 3 klasifikasi biasa dan 1 klasifikasi buruk. Sementara itu, SN bervariasi dari $0-0,993, \mathrm{SP}$ bervariasi dari 0,673 - 0,878 dan PR bervariasi dari 0,688 0,915 . Dalam hal AUC, metode ini sebagian besar menghasilkan klasifikasi yang biasa; sementara dalam hal SN dan PR, metode yang dihasilkan sebagian besar hasilnya rendah; sedangkan dalam hal SP, metode ini menghasilkan hasil yang baik. Namun, berdasarkan hasil, metode ini cukup menjanjikan karena masih menghasilkan 1 klasifikasi yang baik, hanya saja recall (SN) tidak lebih baik daripada precision (PR).

\section{TSC-RUS +B Technique}

Dalam percobaan kedua, kami menerapkan undersampling acak berdasarkan kluster dua langkah (TSCRUS) dan dikombinasikan dengan teknik bagging (TSC-RUS + B). Hasil percobaan ditunjukkan pada Tabel 4 dan Tabel 5 . Confusion matrix dihasilkan untuk lima set data dari Weka dan kemudian kami menghitung SN, SP dan PR, sedangkan AUC langsung dihitung oleh Weka.

Tabel 4. Confusion Matrix TSC-RUS + B

\begin{tabular}{|c|c|c|c|c|}
\hline Dataset & TP & TN & FP & FN \\
\hline CM1 & 110 & 1 & 1 & 215 \\
\hline KC1 & 367 & 4 & 11 & 1727 \\
\hline KC2 & 152 & 5 & 4 & 361 \\
\hline PC1 & 240 & 3 & 9 & 453 \\
\hline MC2 & 112 & 0 & 1 & 12 \\
\hline
\end{tabular}

Tabel 5. Metode Evaluasi untuk TSC-RUS

\begin{tabular}{|c|c|c|c|c|}
\hline Dataset & AUC & SN & SP & PR \\
\hline CM1 & $0,996^{\mathrm{a}}$ & 0,338 & 0.994 & 0.994 \\
\hline KC1 & $0.999^{\mathrm{a}}$ & 0,175 & 0.993 & 0.993 \\
\hline KC2 & $0.995^{\mathrm{a}}$ & 0.296 & 0.983 & 0.983 \\
\hline PC1 & $0.995^{\mathrm{a}}$ & 0,346 & 0.983 & 0.983 \\
\hline MC2 & $1.000^{\mathrm{a}}$ & 0.903 & 0.992 & 0.992 \\
\hline
\end{tabular}

Seperti yang ditunjukkan pada Tabel 5, percobaan kedua menghasilkan hasil yang lebih baik di semua evaluasi daripada percobaan pertama. Dalam hal AUC, 5 diklasifikasikan sebagai sangat baik. SN bervariasi dari 0,175 - 0.903; SP bervariasi dari 0,983 - 0,994 dan PR bervariasi dari 0,992 - 0,994. Dalam soal SN dan PR, percobaan kedua menghasilkan lebih sedikit nilai lebih rendah dan lebih tinggi di nilai atas daripada percobaan pertama. Sedangkan dalam hal SP, percobaan kedua menghasilkan nilai lebih tinggi dan nilai lebih tinggi daripada percobaan pertama.

\section{Perbandingan Hasil Eksperimen} Untuk perbandingan lebih rinci antara percobaan pertama dan kedua, kami menyajikan perbandingan pada Tabel 6 . Font tebal menunjukkan nilai terbaik untuk setiap evaluasi. Seperti yang ditunjukkan pada Tabel 6, percobaan kedua (TSC-RUS $+B$ ) lebih baik dari semua dataset dalam hal AUC.

Tabel 6. Hasil Komparasi Tehnik Bagging vs TSC -RUS + B

\begin{tabular}{ccccccc}
\hline $\begin{array}{c}\text { Data } \\
\text { set }\end{array}$ & \multicolumn{2}{c}{ AUC } & \multicolumn{2}{c}{ SN } & \multicolumn{2}{c}{ SP } \\
& $\mathbf{( 1 )}$ & $\mathbf{( 2 )}$ & $\mathbf{( 1 )}$ & $\mathbf{( 2 )}$ & $\mathbf{( 1 )}$ & $\mathbf{( 2 )}$ \\
\hline \multirow{3}{*}{} & 0,7 & $\mathbf{0 , 9}$ & & $\mathbf{0 , 3}$ & 0,8 & $\mathbf{0 . 9}$ \\
$\mathrm{CM} 1$ & $\mathbf{7 8}$ & $\mathbf{9 6}$ & 0 & $\mathbf{3 8}$ & 12 & $\mathbf{9 4}$ \\
& 0,7 & $\mathbf{0 . 9}$ & $\mathbf{0 , 9}$ & 0,1 & 0,8 & $\mathbf{0 . 9}$ \\
$\mathrm{KC} 1$ & 62 & $\mathbf{9 9}$ & $\mathbf{9 3}$ & 75 & 48 & $\mathbf{9 3}$ \\
& 0,7 & $\mathbf{0 . 9}$ & $\mathbf{0 , 9}$ & 0.2 & 0,7 & $\mathbf{0 . 9}$ \\
$\mathrm{KC} 2$ & 68 & $\mathbf{9 5}$ & $\mathbf{4 0}$ & 96 & $\mathbf{9 7}$ & $\mathbf{8 3}$ \\
& 0,8 & $\mathbf{0 . 9}$ & 0,0 & $\mathbf{0 , 3}$ & 0,8 & $\mathbf{0 . 9}$ \\
$\mathrm{PC} 1$ & 47 & $\mathbf{9 5}$ & 03 & $\mathbf{4 6}$ & 78 & $\mathbf{8 3}$ \\
& 0,6 & $\mathbf{1 . 0}$ & 0,2 & $\mathbf{0 . 9}$ & 0,6 & \\
$\mathrm{MC} 2$ & 62 & $\mathbf{0 0}$ & 09 & $\mathbf{0 3}$ & $\mathbf{7 3}$ & $\mathbf{0 . 9 9 2}$ \\
\hline
\end{tabular}

(1) Teknik bagging, (2) TSC-RUS+ B

Dalam hal $S N$, percobaan kedua mengungguli percobaan pertama di hampir 
semua dataset (3 dari 5 dataset). Sementara itu, dalam hal SP, percobaan pertama tidak mengungguli percobaan kedua di semua dataset. Secara keseluruhan percobaan kedua mengungguli dan lebih baik daripada percobaan pertama karena evaluasi utama dalam klasifikasi kelas yang tidak seimbang seperti SDP adalah AUC sebagaimana dinyatakan oleh (Rana et al., 2015), (Lessmann et al., 2008).

\section{Kesimpulan}

Metode hybrid baru yang mengintegrasikan two-step clusteringbased dan bagging technique sebagai pendekatan algoritma diusulkan dalam makalah ini, untuk meningkatkan akurasi prediksi cacat perangkat lunak. Metode yang diusulkan diterapkan untuk menangani masalah ketidakseimbangan kelas di SDP. Hasil percobaan menunjukkan bahwa metode yang diusulkan menghasilkan peningkatan dalam kinerja prediksi untuk sebagian besar dataset.

\section{Referensi}

Arar, Ö. F., \& Ayan, K. (2015). Software defect prediction using cost-sensitive neural network. Applied Soft Computing Journal, 33, 263-277. https://doi.org/10.1016/j.asoc.2015.04. 045

Barandela, R., Sánchez, J. S., \& Valdovinos, R. M. (2003). New Applications of Ensembles of Classifiers. Pattern Analysis and Applications, 6(3), 245-256. https://doi.org/10.1007/s10044-0030192-z

Bbeiman, L. E. O. (1996). Bagging Predictors, 140, 123-140.

Catal, C. (2011). Expert Systems with Applications Software fault prediction: A literature review and current trends. Expert Systems With Applications, 38(4), 4626-4636. https://doi.org/10.1016/j.eswa.2010.10. 024

Chawla, N. V, Lazarevic, A., Hall, L. O., \& Bowyer, K. W. (n.d.). SMOTEBoost: Improving Prediction, 107-119.

Chiu, T., Fang, D., Chen, J., Wang, Y., \& Jeris, C. (2001). A robust and scalable clustering algorithm for mixed type attributes in large database environment. Proceedings of the Seventh ACM SIGKDD International Conference on Knowledge Discovery and Data Mining - KDD '01, 263-268. https://doi.org/10.1145/502512.502549

Czibula, G., Marian, Z., \& Czibula, I. G. (2014). Software defect prediction using relational association rule mining. Information Sciences, 264, 260-278.

https://doi.org/10.1016/j.ins.2013.12.03 1

Galar, M., Fern, A., Barrenechea, E., \& Bustince, H. (2012). Hybrid-Based Approaches, 42(4), 463-484.

Gorunescu, F. (2011). Data Mining: Concepts,Models and Techniques. Berlin: Springer-Verlag Berlin Heidelberg. https://doi.org/10.1360/zd2013-43-6-1064

Hartigan, J. A., \& Wong, M. A. (1979). Algorithm AS 136: A K-Means Clustering Algorithm. Applied Statistics, $\quad 28(1), \quad 100$. https://doi.org/10.2307/2346830

Hu, S. (2009). 2009 Second International Workshop on Computer Science and Engineering MSMOTE: Improving Classification Performance when Training Data is imbalanced, 627-631. https://doi.org/10.1109/WCSE.2009.75 6

Jain, A, K., Murty, M, P., \& Flynn, P, J. (1999). Data clustering: a review. ACM Computing Surveys, 31(3), 264-323. https://doi.org/10.1145/345966.346030

Laradji, I. H., Alshayeb, M., \& Ghouti, L. (2015). Software defect prediction using ensemble learning on selected features. Information and Software Technology, 58, 388-402. https://doi.org/10.1016/j.infsof.2014.07. 005

Learning, C., Liu, X., Wu, J., Zhou, Z., \& Member, S. (2009). Exploratory Undersampling for, 39(2), 539-550.

Lessmann, S., Baesens, B., Mues, C., \& Pietsch, S. (2008). Benchmarking classification models for software defect prediction: A proposed framework and novel findings. IEEE Transactions on Software Engineering, 34(4), 485-496. https://doi.org/10.1109/TSE.2008.35

Li, D., Liu, C., \& Hu, S. C. (2010). A learning method for the class imbalance problem with medical data 
sets. Computers in Biology and Medicine, 40(5), 509-518. https://doi.org/10.1016/j.compbiomed.2 010.03.005

Lin, W., Tsai, C., Hu, Y., \& Jhang, J. (2017). Clustering-based undersampling in class-imbalanced data, 410, 17-26. https://doi.org/10.1016/j.ins.2017.05.0 08

Michailidou, C., Maheras, P., ArseniPapadimititriou, A., Kolyva-Machera, F., \& Anagnostopoulou, C. (2009). A study of weather types at Athens and Thessaloniki and their relationship to circulation types for the cold-wet period, part I: Two-step cluster analysis. Theoretical and Applied Climatology, 97(1-2), 163-177. https://doi.org/10.1007/s00704-0080057-x

Rana, Z. A., Mian, M. A., \& Shamail, S. (2015). Improving Recall of software defect prediction models using association mining. Knowledge-Based Systems, 90, 1-13. https://doi.org/10.1016/j.knosys.2015. 10.009

Satish, S. M., \& Bharadhwaj, S. (2010). Information search behaviour among new car buyers: A two-step cluster analysis. IIMB Management Review, 22(1-2), 5-15. https://doi.org/10.1016/j.iimb.2010.03. 005

Schapire, R. E. (1990). The Strength of Weak Learnability, 227, 197-227.
Seiffert, C., Khoshgoftaar, T. M., Hulse, J. Van, \& Napolitano, A. (2010). RUSBoost: A Hybrid Approach to Alleviating, $\quad 40(1), \quad 185-197$. https://doi.org/10.1109/TSMCA.2009.2 029559

Siers, M. J., \& Islam, Z. (2015). Software defect prediction using a cost sensitive decision forest and voting and a potential solution to the class imbalance problem. Information Systems, $1-10$. https://doi.org/10.1016/j.is.2015.02.00 6

Solis, J., Avizzano, C. A., \& Bergamasco, M. (2002). Diversity Analysis on Imbalanced Data Sets by Using Ensemble Models. Proceedings - 10th Symposium on Haptic Interfaces for Virtual Environment and Teleoperator Systems, HAPTICS 2002, 255-262. https://doi.org/10.1109/HAPTIC.2002. 998966

Sun, Z., Song, Q., Zhu, X., Sun, H., Xu, B., \& Zhou, Y. (2015). A novel ensemble method for classifying imbalanced data. Pattern Recognition, 48(5), 1623-1637. https://doi.org/10.1016/j.patcog.2014.1 1.014

Wahono, R. S., \& Herman, N. S. (2014). Genetic feature selection for software defect prediction. Advanced Science Letters, 20(1), 239-244. https://doi.org/10.1166/asl.2014.5283 